\title{
Superconducting Dy1-x(Gd,Yb)xBa2Cu307- thin films made by Chemical Solution Deposition
}

Opata, Yuri Aparecido; Wulff, Anders Christian; Hansen, Jørn Otto Bindslev; Yue, Zhao; Grivel, JeanClaude

Published in:

I E E E Transactions on Applied Superconductivity

Link to article, DOI:

10.1109/TASC.2016.2549558

Publication date:

2016

Document Version

Peer reviewed version

Link back to DTU Orbit

Citation (APA):

Opata, Y. A., Wulff, A. C., Hansen, J. O. B., Yue, Z., \& Grivel, J-C. (2016). Superconducting Dy

$(\mathrm{Gd}, \mathrm{Yb}) \mathrm{Ba}_{\mathrm{Cu}} \mathrm{Cu}_{3}$ thin films made by Chemical Solution Deposition. I E E E Transactions of Applied Superconductivity', 26(3), [7500705]. https://doi.org/10.1109/TASC.2016.2549558

\section{General rights}

Copyright and moral rights for the publications made accessible in the public portal are retained by the authors and/or other copyright owners and it is a condition of accessing publications that users recognise and abide by the legal requirements associated with these rights.

- Users may download and print one copy of any publication from the public portal for the purpose of private study or research.

- You may not further distribute the material or use it for any profit-making activity or commercial gain

- You may freely distribute the URL identifying the publication in the public portal 


\title{
Superconducting $\mathrm{Dy}_{1-x}(\mathrm{Gd}, \mathrm{Yb})_{x} \mathrm{Ba}_{2} \mathrm{Cu}_{3} \mathrm{O}_{7-\delta}$ thin films made by Chemical Solution Deposition
}

\author{
Yuri A. Opata, Anders C. Wulff, Jørn B. Hansen, Zhao Yue and Jean-Claude Grivel
}

\begin{abstract}
Dy $\mathbf{y}_{1-x}(\mathrm{Gd} \text { or } \mathrm{Yb})_{x} \mathrm{Ba}_{2} \mathrm{Cu}_{3} \mathrm{O}_{7-\delta}$ samples were prepared using chemical solution deposition (CSD), based on trifluoroacetate metal-organic decomposition (MOD) methods. Xray diffraction results demonstrated the formation of the RE123 superconducting phase with a strong in-plane and out-of-plane texture. c-lattice constants were observed to decrease for all samples doped with Gd or Yb. Measurements of the onset critical transition temperature $\left(T_{c}^{\text {onset }}\right)$ were found to decrease with increasing Yb content, while only minor changes were observed for samples with $\mathbf{G d}$. Critical current density $\left(\mathbf{J}_{c}\right)$ analysis demonstrated that doping with $\mathrm{Yb}$ significantly increased the self-field $J_{c}$ value from $3.8 \mathrm{MA} / \mathrm{cm}^{2}$ to $6.0 \mathrm{MA} / \mathrm{cm}^{2}$ for the pure and $10 \% \mathrm{Yb}$ doped sample, respectively. In contrast, samples doped with $G d$ were characterized by the lowest self-field $\mathbf{J}_{c}$ values. Investigation of pinning force mechanisms revealed that the samples in this study were dominated by normal surface pinning.
\end{abstract}

Index Terms-Superconducting, thin film, pinning force, doping, critical current density.

\section{INTRODUCTION}

C HEMICAL solution deposition (CSD), based on trifluoroacetate metal-organic decomposition (MOD), is considered one of the most cost effective and scalable solutions for industrial production of long length and uniform superconducting coated conductors (CCs) with a high critical current $\left(\mathrm{I}_{c}\right)$ [1]-[4]. The latter is achieved by epitaxially growing a thin superconducting rare-earth- $\mathrm{Ba}_{2} \mathrm{Cu}_{3} \mathrm{O}_{7-\delta}$ (RE123) film on a strongly textured template. Improving the performance of the $\mathrm{CC}$ can be achieved by increasing $\mathrm{I}_{c}$ either by producing thicker RE123 layers or increasing the critical current density $\mathrm{J}_{c}$. Increasing the film thickness using CSD-MOD has proved difficult [2] compared to other deposition techniques [5], [6], while introducing artificial pinning centers by doping the RE123 has been demonstrated to significantly improve the inmagnetic-field $\mathrm{J}_{c}$. Doping is typically performed either by RE [7]-[9] or $\mathrm{Cu}$ [10]-[12] substitution, or by adding elements, such as $\mathrm{Zr}$ or $\mathrm{Y}$, to form non-superconducting nanopartiles [13]. Most work on increasing $\mathrm{J}_{c}$ of RE123 films has been focused on RE-substitutions and doping with nanoparticles in $\mathrm{YBa}_{2} \mathrm{Cu}_{3} \mathrm{O}_{7-\delta}$ (Y123) [14], [15] and $\mathrm{GdBa}_{2} \mathrm{Cu}_{3} \mathrm{O}_{7-\delta}$ (Gd123) [16]. Such investigations in $\mathrm{DyBa}_{2} \mathrm{Cu}_{3} \mathrm{O}_{7-\delta}$ (Dy123) have mainly been conducted on thin films made by inclined

This work was supported by the Brazilian program Science without borders - Proc. Number BEX 13491/13-0 - and Department of Energy Conversion and Storage of Technical University of Denmark - DTU

Y. A. Opata, A. C. Wulff, Y. Zhao and J.-C. Grivel are with Department of Energy Conversion and Storage, Technical University of Denmark - DTU, Denmark, email: yaop@dtu.dk

J. B. Hansen is with Department of Physics, Technical University of Denmark - DTU, Denmark. substrate deposition (ISD), thermal evaporation and molecular beam epitaxy [17]-[20]. The present work will focus on the changes in the structural and pinning properties of CSD-based $\mathrm{Dy}_{1-x}(\mathrm{Gd}, \mathrm{Yb})_{x} \mathrm{Ba}_{2} \mathrm{Cu}_{3} \mathrm{O}_{7-\delta}$ thin films resulting from partial substitution of $\mathrm{Dy}^{+3}$ by $\mathrm{Gd}^{+3}$ and $\mathrm{Yb}^{+3}$ ions.

\section{EXPERIMENTAL PROCEDURE}

$$
\mathrm{Dy}_{1-x} \mathrm{Gd}_{x} \mathrm{Ba}_{2} \mathrm{Cu}_{3} \mathrm{O}_{7-\delta} \quad \text { (DyGd) }
$$

and

$\mathrm{Dy}_{1-x} \mathrm{Yb}_{x} \mathrm{Ba}_{2} \mathrm{Cu}_{3} \mathrm{O}_{7-\delta}$ (DyYb), with $\mathrm{x}=0,0.1$ and 0.2, thin films were synthesized by a metal-organic decomposition route [21]. The solutions were prepared as follows. Firstly, stoichiometric amounts of dysprosium, gadolinium and ytterbium acetate tetrahydrate and barium acetate were dissolved in trifluoroacetic anhydride and deionized water and stirred for 2 hours at $50{ }^{\circ} \mathrm{C}$. Secondly, copper acetate monohydrate was dissolved in acrylic acid and deionized water and stirred for 1 hour at $80{ }^{\circ} \mathrm{C}$. After reaction the copper solution was dried by vacuum evaporation resulting in a viscous blue liquid. This process was also used to dry the dysprosium, gadolinium, ytterbium and barium solutions. The copper solution was then dissolved in methanol (99\%) and mixed with the dysprosium (gadolinium, ytterbium)-barium solution and drying using vacuum evaporation. The final solution volume was adjusted to $1.5 \mathrm{M}$ by adding methanol (99.9\%). The precursor solutions were deposited on $\mathrm{LaAlO}_{3}$ (LAO) single crystalline substrates at room temperature by spin-coating at $5000 \mathrm{rpm}$. Pyrolysis was performed by heating the sample in a furnace from room temperature to $180^{\circ} \mathrm{C}$ at $5^{\circ} \mathrm{C} / \mathrm{min}$, followed by a ramp to $350^{\circ} \mathrm{C}$ at $2.1^{\circ} \mathrm{C} / \mathrm{min}$ and then to $400^{\circ} \mathrm{C}$ at $2^{\circ} \mathrm{C} / \mathrm{min}$. The furnace was kept at this temperature for 10 minutes, followed by cooling to room temperature. A humid oxygen flow was switched on at $100^{\circ} \mathrm{C}$ and kept until $400^{\circ} \mathrm{C}$, ending the process with dry oxygen. After the pyrolysis, the films were subjected to a crystallization and sintering process, where the temperature was increased from room temperature to $720^{\circ} \mathrm{C}$ at $28^{\circ} \mathrm{C} / \mathrm{min}$, followed by heating with $18^{\circ} \mathrm{C} / \mathrm{min}$ to $810^{\circ} \mathrm{C}$. The latter temperature was kept for 135 min, ending with furnace cooling to room temperature. In this process, humid argon with $300 \mathrm{ppm}$ of $\mathrm{O}_{2}$ gas was used, switched on at $400^{\circ} \mathrm{C}$ and kept on until 30 minutes before the end of the process. During the last period the gas was dry in order to sinter the composites. Finally, oxygenation was carried out at $450^{\circ} \mathrm{C}$ for 3 hours in an oxygen flow.

Phase and crystallographic textures were analysed by X-ray diffraction (XRD) using $\mathrm{Cu} \mathrm{K}_{\alpha}$ radiation source, in a Rigaku four-circle diffractometer. Scanning electron microscopy images were acquired (SEM, Supra 35) to analyze the surface 
morphology with an in-lens detector. Magnetic properties were characterized in a vibrating sample magnetometer (VSM), where the superconducting transition temperature was determined using an AC susceptibility technique with an applied magnetic field amplitude of $0.1 \mathrm{mT}$ and a frequency of $17 \mathrm{~Hz}$. $\mathbf{J}_{c}$ values were calculated using the Bean model. Analysis of the pinning force was also carried out [22].

\section{RESUlTS AND Discussion}

XRD patterns of all samples are presented in Fig. 1, where the $(00 l)$ reflections from the RE123 superconducting phase are indicated. These results show that RE123 phase formation was achieved, with strong c-axis orientation. Additionally, significant peaks from the single crystal substrate (LAO), and some minor reflections, due to RE123 (103) and (200) (see inset in Fig. 1) and $\mathrm{Dy}_{2} \mathrm{O}_{3}$ (400) were observed for all films. From the $(00 l)$ RE123 peaks positions, the c-axis lattice constant was calculated with the Nelson-Riley method [23]. The results are shown Fig. 2, as a function of the average ionic radius of the rare-earth nominal composition $\mathrm{Dy}_{1-x}(\mathrm{Gd}, \mathrm{Yb})_{x}$. For the $\mathrm{Yb}$-doped films it is noticed that the c-axis value is reduced with the increase of the $x$ doping level, which can be ascribed to the smaller ion radius of $\mathrm{Yb}^{+3}(0.985 \AA)$ as compared to $\mathrm{Dy}^{+3}(1.027 \AA$ ) [24]. In case of Gd-doped films, a reduction in c-axis is first observed $(c \approx 11.6855)$, followed by an increase $(c \approx 11.6889)$. An increase of the $\mathrm{c}$ lattice parameter would be expected, as observed in related doping studies [8], [25], because $\mathrm{Gd}^{+3}$ has an ion radius (1.057 $\AA$ ) larger than $\mathrm{Dy}^{+3}$. This could be due to a partial replacement of Gd ions on Ba sites instead of Dy [26], [27], whereas there is not possibility for such ion exchange between $\mathrm{Dy}$ and $\mathrm{Ba}$ [28], [29].

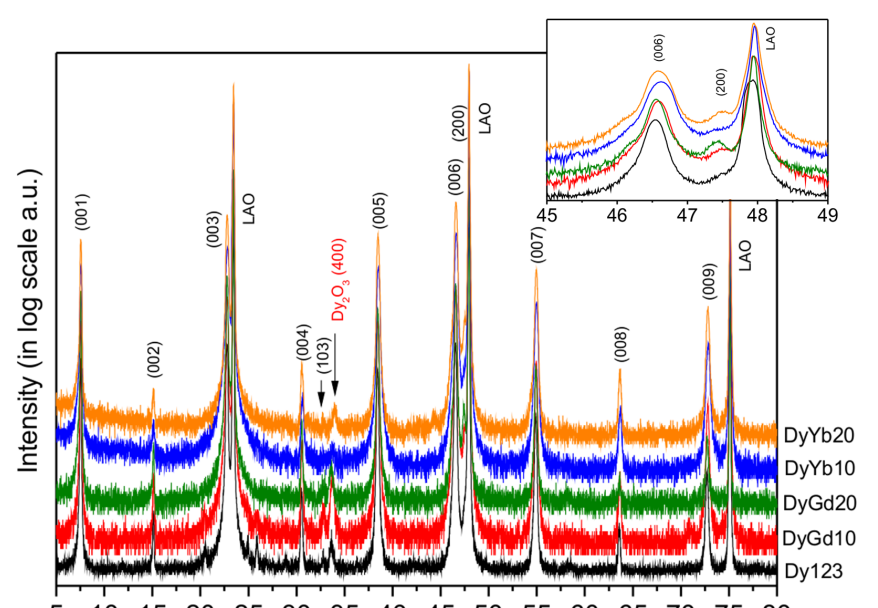

$\begin{array}{llllllllllllllll}5 & 10 & 15 & 20 & 25 & 30 & 35 & 40 & 45 & 50 & 55 & 60 & 65 & 70 & 75 & 80\end{array}$

$2 \theta\left({ }^{\circ}\right)$

Figure 1. XRD diffraction patterns for all samples, where the peaks from films, substrate and other minor reflections are indexed. The inset shows a zoom of the region between $45^{\circ}-49^{\circ}$, which shows the variation of the RE123 (200) peak.

The texture quality of the samples was investigated by (103) phi-scans and (005) rocking curves. Details of the texture analysis are presented in Table I. The full width at half

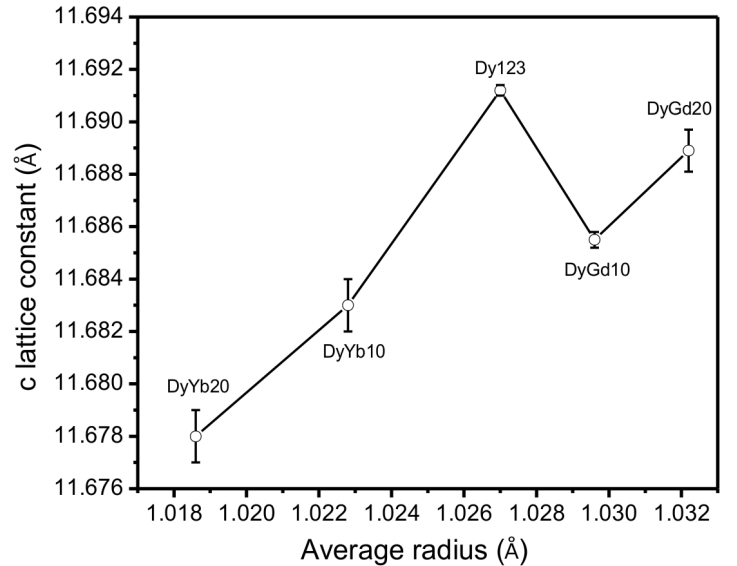

Figure 2. c-lattice constant - calculed from the Nelson-Riley method - as a function of the average ionic radius of nominal composition $\mathrm{Dy}_{1-x}(\mathrm{Gd}, \mathrm{Yb})_{x}$.

maximum values (FWHM) demonstrate that a good in-plane $(\Delta \phi)$ and out-of-plane $(\Delta \omega)$ alignment is present in all films. An increase of the $\Delta \phi$ values are observed for doping with $\mathrm{Yb}$ and $\mathrm{Gd}$, indicates a degradation of the in-plane texture due to lattice deformation caused by the doping [7].

Table I

DETAILS OF TEXTURE ANALYSIS FOR ALL THIN FILMS.

\begin{tabular}{ccc}
\hline Sample & $\Delta \phi$ FWHM & $\Delta \omega$ FWHM \\
\hline Dy123 & $0.51^{\circ}$ & $0.39^{\circ}$ \\
$\left(\mathrm{Dy}_{0.9} \mathrm{Gd}_{0.1}\right) 123-(\mathrm{DyGd} 10)$ & $1.5^{\circ}$ & $0.74^{\circ}$ \\
$\left(\mathrm{Dy}_{0.8} \mathrm{Gd}_{0.2}\right) 123-(\mathrm{DyGd} 20)$ & $1.62^{\circ}$ & $0.58^{\circ}$ \\
$\left(\mathrm{Dy}_{0.9} \mathrm{Yb}_{0.1}\right) 123-(\mathrm{DyYb10})$ & $0.54^{\circ}$ & $0.26^{\circ}$ \\
$\left(\mathrm{Dy}_{0.8} \mathrm{Yb}_{0.2}\right) 123-(\mathrm{DyY} \mathrm{Y} 20)$ & $1.32^{\circ}$ & $0.3^{\circ}$ \\
\hline
\end{tabular}

Fig. 3 a-e shows the surface morphology for the $\mathrm{DyBa}_{2} \mathrm{Cu}_{3} \mathrm{O}_{7-\delta}$ and $(\mathrm{Gd}, \mathrm{Yb})$-doped films. A crack-free and dense surface is observed for all films. Some $a / b$-axis oriented grains (white solid ellipse) are observed, as confirmed also by the XRD data. It is found that the particles (white dashed circles) and the fraction of pores are reduced with the increasing of doping level, except in the DyYb10 case, where an increase in the particles is observed. The reason behind the modification of the density of the pores is not clear, but it might be related to the difference in peritectic melting values, being $1020^{\circ} \mathrm{C}$, $1010^{\circ} \mathrm{C}$ and $950^{\circ} \mathrm{C}$ to $\mathrm{Gd} 123$, Dy 123 and $\mathrm{Yb} 123$ respectively [30]. Film thickness analysis was performed by SEM crosssection observation after mechanically breaking the films, as shown in Fig. 3f for the DyGd20 sample. The average of thickness was calculed using the values measured along the entire length of each film. An average value of $320 \mathrm{~nm}$ was found for the films, except of the DyYb10 sample, which exhibits a value around $270 \mathrm{~nm}$.

Real part of AC magnetic susceptibility $\left(\chi^{\prime}\right)$ curves are presented in Fig. 4, where the values of susceptibility were normalized at temperature of $40 \mathrm{~K}$. It should be noticed that, except for the pure sample, all films show a narrow superconducting transition with similar $\mathrm{T}_{c}$. The $\mathrm{T}_{c}^{\text {onset }}$ values are presented inset in Fig. 4, as a function of $x$ doping level in the composition $\mathrm{Dy}_{1-x}(\mathrm{Gd}, \mathrm{Yb})_{x} 123$. It was found that the $\mathrm{T}_{c}^{\text {onset }}$ 

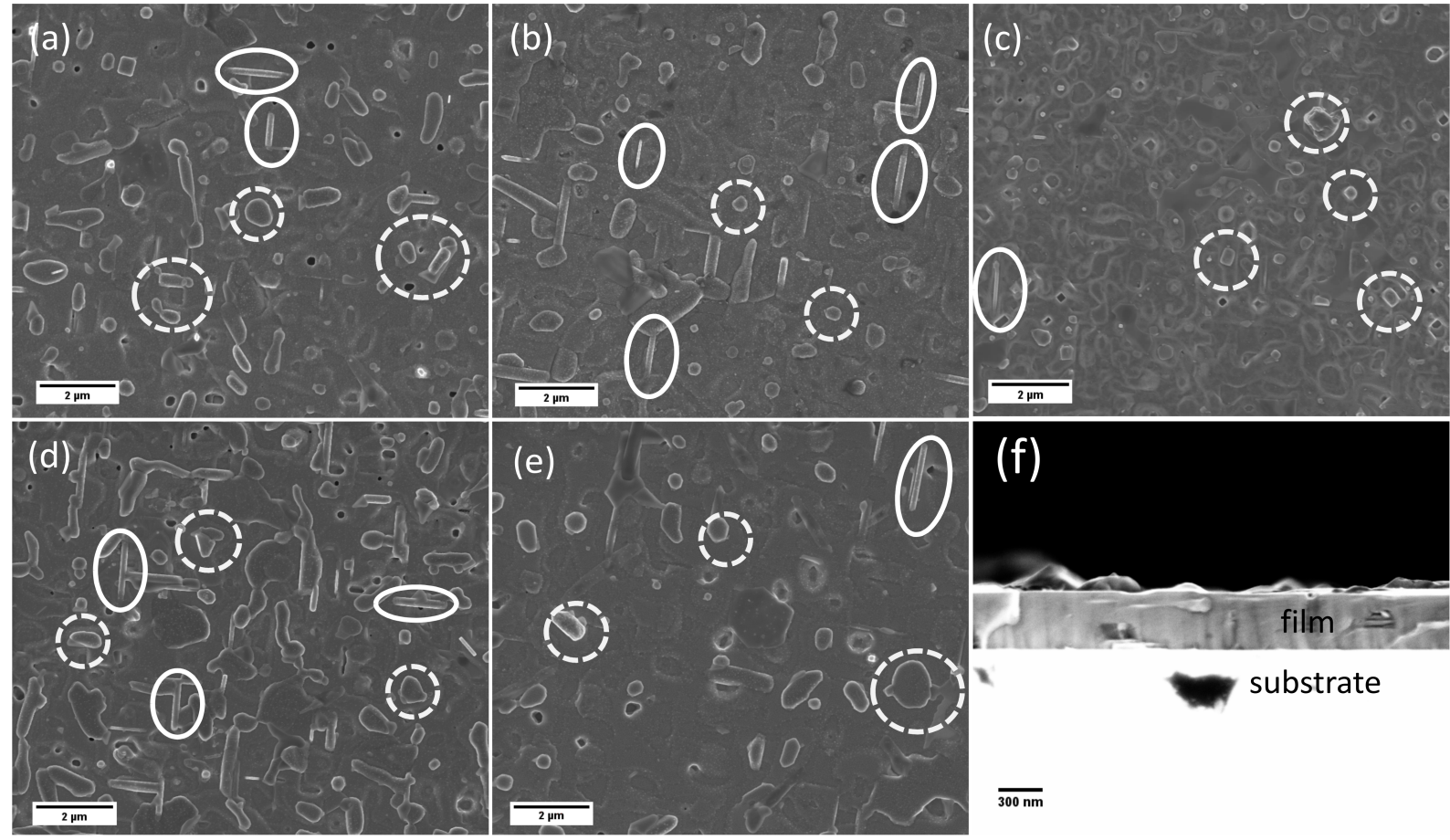

Figure 3. SEM images of the thin films: (a) Dy123; (b) DyGd10; (c) DyGd20; (d) DyYb10 and (e) DyYb20. (f) shows the cross section of sample DyGd20. White dashed circles indicate some particles while white solid ellipses highlight some a/b-axis oriented grains.

value is slightly lowered by $\mathrm{Yb}$-doping, in contrast to Gddoping which seems to have a lower effect on $\mathrm{T}_{c}^{\text {onset }}$ value.

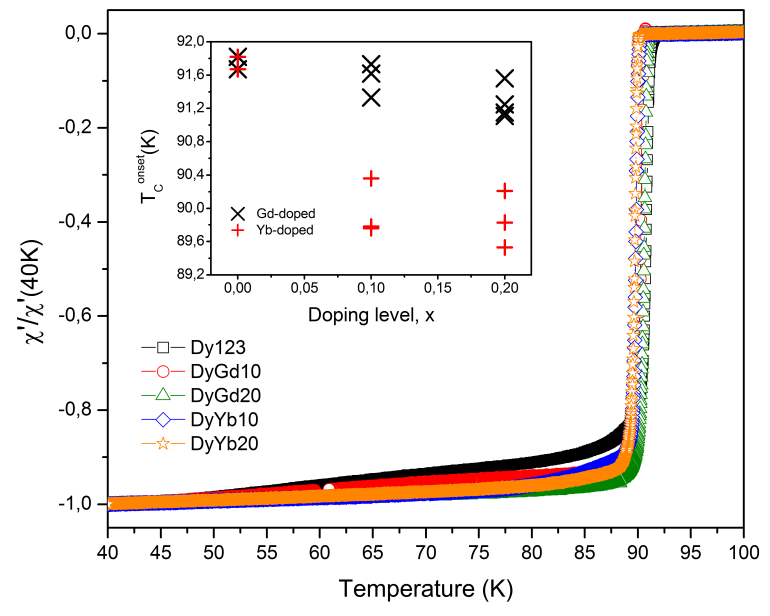

Figure 4. AC susceptibility curves for all investigated films. The inset shows the $\mathrm{T}_{c}^{\text {onset }}$ values as a function of $x$ doping level.

The $\mathbf{J}_{c}$ values, as a function of applied magnetic field for all thin films are shown in Fig. 5. The highest critical current density self-field $\left(\mathrm{J}_{c}^{s f}\right)$ - see inset in Fig. 5 - were observed for the $\mathrm{Yb}$-doped films, with the maximum of $6.0 \mathrm{MA} / \mathrm{cm}^{2}$ in the DyYb10 sample. In contrast, the Gd-doped films exhibit lower values, with $\mathbf{J}_{c}^{s f}=2.61 \mathrm{MA} / \mathrm{cm}^{2}$ for DyGd20. Three different regimes are observed: a plateau at low magnetic field, associated to single-pinning regime, followed by a power-law $\mathrm{J}_{c}(\mathrm{~B}) \sim \mathrm{B}^{-\alpha}$ behaviour (see $\alpha$ values in Fig. 5), assigned to vortices collective interaction, which precedes the rapid decrease of $\mathrm{J}_{c}$, as a result of flux creep [21]. Flux pinning force $\left(\mathrm{F}_{P}=\mathrm{J}_{c} \times \mathrm{B}\right)$ results are shown in Fig. 6 , where the
Yb-doped and pure films exhibit the highest maximum pinning force $\left(\mathrm{F}_{P}^{M a x}\right)$ values at $77 \mathrm{~K}$, whereas the Gd-doped films show lower values. It is suggested that such result could be due to partial substitution of $\mathrm{Gd}$ on the Ba sites, causing a decrease in both $\mathbf{J}_{c}^{s f}$ and $\mathrm{F}_{P}$. On the other hand, the higher $\mathbf{J}_{c}^{s f}$ values observed in DyYb10 film can be assigned to a strong texture $(\Delta \omega)$ observed in this sample, as reported in Table I. This is supported by the low (103) and (200) peaks in Fig. 1. Another possible contribution to the improved $\mathbf{J}_{c}$ is the lower amount of porosity in the Y-doped films, while the large difference in ion size between $\mathrm{Dy}$ and $\mathrm{Yb}(0.042 \AA)$ compared to Dy versus Gd $(0.026 \AA)$ can also have a positive effect [8], [14].

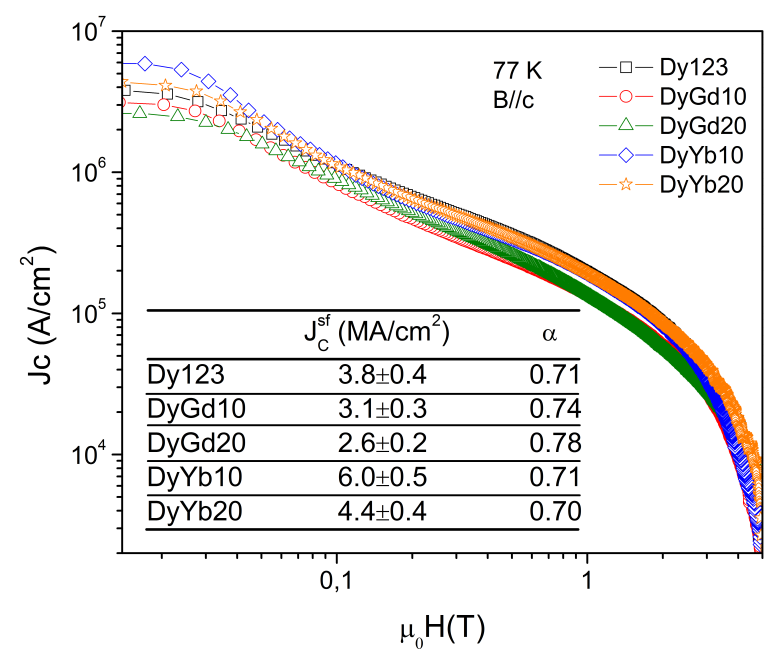

Figure 5. Double logarithmic plot of the critical current density against applied magnetic field at $77 \mathrm{~K}$, for all films. The inset table summarizes the $\mathrm{J}_{c}^{s f}$ and $\alpha$ values of the power-law dependence $\mathrm{J}_{c}(\mathrm{~B}) \sim \mathrm{B}^{-\alpha}$. 


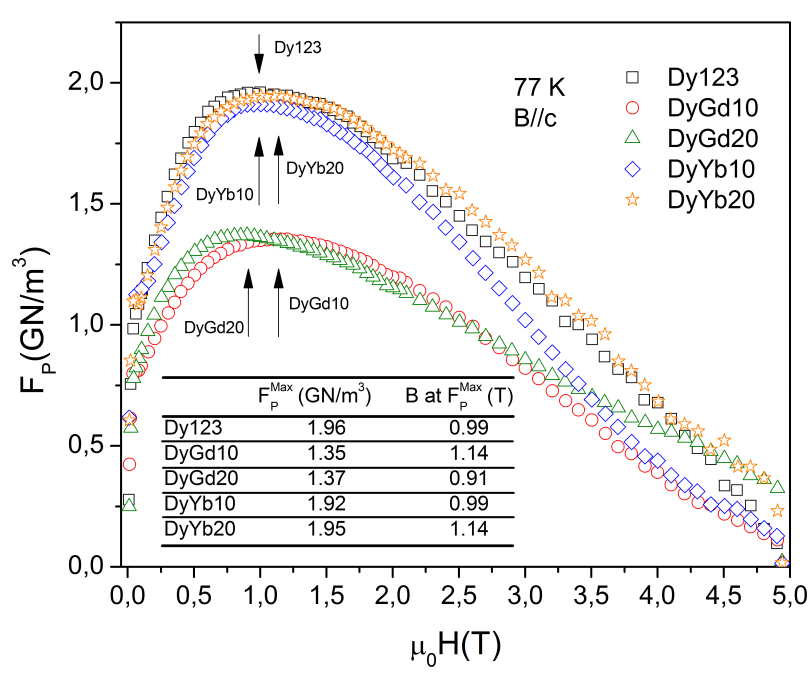

Figure 6. Flux pinning force as a function of applied magnetic field at $77 \mathrm{~K}$. The inset table presents the $\mathrm{F}_{P}^{M a x}$ and magnetic field value, indicated by the arrows in the graphic, at maximum pinning force position.

To analyse the flux pinning mechanism, we applied a modified Kramer and Dew-Hughes model [22], where the curve of $f=\mathrm{F}_{P} / \mathrm{F}_{P}^{M a x}$ vs $h=\mathrm{B} / \mathrm{B}^{*}$ is fitted according to equation

$$
f=\sum_{i=1}^{6} a_{i} h^{p_{i}}(1-h)^{q_{i}}
$$

The $\mathrm{B}^{*}$ values were determined by plotting $\mathrm{J}_{c}^{1 / 2} B^{1 / 4}$ vs B [31], [32]. The parameters $p_{i}$ and $q_{i}$ are associated to different kinds of pinning mechanisms depending on their values [33], as listed below:

$\mathrm{p}_{1}=0, \mathrm{q}_{1}=2$ : normal, volume pinning $\left(\mathrm{V}_{N}\right)$;

$\mathrm{p}_{2}=1, \mathrm{q}_{2}=1: \Delta \kappa$, volume pinning $\left(\mathrm{V}_{k}\right)$;

$\mathrm{p}_{3}=1 / 2, \mathrm{q}_{3}=2$ : normal, surface pinning $\left(\mathrm{S}_{N}\right)$;

$\mathrm{p}_{4}=3 / 2, \mathrm{q}_{4}=1: \Delta \kappa$, surface pinning $\left(\mathrm{S}_{k}\right)$;

$\mathrm{p}_{5}=1, \mathrm{q}_{5}=2$ : normal, point pinning $\left(\mathrm{P}_{N}\right)$;

$\mathrm{p}_{6}=2, \mathrm{q}_{6}=1: \Delta \kappa$, point pinning $\left(\mathrm{P}_{k}\right)$;

The $a_{i}$ constants represent the weight of each kind of pinning mechanism and $a_{j}(\%)=100 \times \sum_{i=1}^{6}\left(a_{j} / a_{i}\right)$ represent the percentage contribution of each pinning mechanism, reported as $\mathrm{V}_{N, k}, \mathrm{~S}_{N, k}$ or $\mathrm{P}_{N, k}$. The fitted results for the different flux pinning mechanisms are listed in Table II, together with the $\mathrm{B}^{*}$ and $\mathrm{h}$ (at $\mathrm{F}_{P}^{M a x}$ position) values. These results indicate that the pinning mechanism is dominated by normal surface pinning $\left(\mathrm{S}_{N}\right)$, in agreement with [7], [11], [34] who attributed this effect to be a result of dislocations. In this work, it is observed that the $\mathrm{S}_{N}$ values are lower than compared to the un-doped Dy123 sample for the investigated range of doping levels (10-20\%). This indicates that the details of the the flux pinning mechanism are affected by doping, however the main pinning mechanism remain the same, whereas subtle variations cannot be inferred with certainty due to the large number of fitting parameters included in the model. Some differences in pinning could be assigned to the presence of nanoparticles, as for example $\mathrm{RE}_{2} \mathrm{O}_{3}$ or inclusions of $\mathrm{Cu}$ - rich phases [34], or also slight variations in the texture of the sample.

Table II

CONTRIBUTION OF EACH PINNING MECHANISM CALCULATED FROM EQUATION (1). IT IS ALSO INCLUDE THE B* AND H (AT F Max POSITION) VALUES.

\begin{tabular}{cccccc}
\hline & Dy123 & DyGd10 & DyGd20 & DyYb10 & DyYb20 \\
\hline $\mathrm{B}^{*}(\mathrm{~T})$ & 6.12 & 5.93 & 6.78 & 5.50 & 6.29 \\
$\mathrm{~h}$ at $\mathrm{F}_{P}^{\text {Max }}$ & 0.16 & 0.19 & 0.13 & 0.18 & 0.18 \\
$\mathrm{~V}_{N}(\%)$ & 6 & 7 & 11 & 5 & 7 \\
$\mathrm{~V}_{k}(\%)$ & - & 9 & - & - & 11 \\
$\mathrm{~S}_{N}(\%)$ & 94 & 75 & 86 & 77 & 81 \\
$\mathrm{~S}_{k}(\%)$ & - & - & - & - & 1 \\
$\mathrm{P}_{N}(\%)$ & - & 9 & - & 16 & - \\
$\mathrm{P}_{k}(\%)$ & - & - & 3 & 2 & - \\
\hline
\end{tabular}

\section{CONCLUSION}

In this work, we investigated the changes in structural properties and variations in the magnetic flux pinning mechanism caused by the substitution of $\mathrm{Gd}$ and $\mathrm{Yb}$ ions (10$20 \%)$ in superconducting $\mathrm{Dy}_{1-x}(\mathrm{Gd}, \mathrm{Yb})_{x} \mathrm{Ba}_{2} \mathrm{Cu}_{3} \mathrm{O}_{7-\delta}$ thin films, prepared by trifluoroacetate metal-organic decomposition methods. XRD $\theta-2 \theta$ line profile analysis demonstrated that the samples exhibited the 123-phase. Strong in-plane and out-of-plane textures were observed for all the thin films, with the lowest full-width-at-half-maximum values obtained for the $\mathrm{Dy}_{0.9} \mathrm{Yb}_{0.1} \mathrm{Ba}_{2} \mathrm{Cu}_{3} \mathrm{O}_{7-\delta}$ sample. From a comparison of the clattice constants (c) it is evident that this parameter decreases upon doping with $10-20 \% \mathrm{Yb}$ or $\mathrm{Gd}$ in the $\mathrm{DyBa}_{2} \mathrm{Cu}_{3} \mathrm{O}_{7-\delta}$ thin films. Using vibrating sample magnetometer analysis it was proved that doping with $\mathrm{Yb}$, in this range, significantly decreased the onset critical temperature, while this value was nearly unaffected upon doping with Gd. In contrast, the critical current density values $\left(\mathrm{J}_{c}\right)$, at self-field, for the samples with Yb-doping were larger than the un-doped one, with the maximum $\mathrm{J}_{c}(77 \mathrm{~K})=6.0 \mathrm{MA} / \mathrm{cm}^{2}$ (self-field) for the sample with $10 \%$ Yb. Compared to the un-doped film, both Gd-doped samples showed lower $\mathbf{J}_{c}$ values in self-field. Flux pinning force analysis showed that also the highest pinning force was observed in the samples with $\mathrm{Yb}$ (more than $1.9 \mathrm{GN} / \mathrm{m}^{3}$ ), while the lowest pinning force value was observed for the sample with $10 \% \mathrm{Gd}\left(1.35 \mathrm{GN} / \mathrm{m}^{3}\right)$. Finally, a flux pinning model was applied to the pinning force curves and it was found that normal surface pinning was the dominating pinning mechanism in all the films, with only minor contributions from point pinning detected for the samples with $10 \%$ doping.

\section{REFERENCES}

[1] J. Gutirrez, A. Llords, J. Gzquez, M. Gibert et al. "Strong isotropic flux pinning in solution-derived $\mathrm{YBa}_{2} \mathrm{Cu}_{3} \mathrm{O}_{7-x}$ nanocomposite superconductor films", Nat Mater., vol. 6, 367-373 (2007).

[2] M. W. Rupich, Xiaoping Li, S. Sathyamurthy, C. L. H. Thieme, K. DeMoranville, J. Gannon and S. Fleshler. "Second Generation Wire Development at AMSC", IEEE Trans. Appl. Supercond., vol. 23, no. 3 (2013) Art. ID: 6389758. 
[3] I. Bretos, T. Schneller, M. Falter, M. Bcker, E. Hollmann, R. Wrdenweber, L. Molina-Luna, G. V. Tendeloo and O. Eibl. "Solution-derived $\mathrm{YBa}_{2} \mathrm{Cu}_{3} \mathrm{O}_{7-d}$ (YBCO) superconducting films with $\mathrm{BaZrO}_{3}$ (BZO) nanodots based on reverse micelle stabilized nanoparticles", J. Mater. Chem. C, vol. 3, 3971-3979 (2015).

[4] T. Schneller, R. Waser, M. Kosec and D. Payne. Chemical Solution Deposition of Functional Oxide Thin Films. Springer; 2013 edition (2014).

[5] Z. Aabdin, M. Drrschnabel, M. Bauer, R. Semerad, W. Prusseit and O. Eibl. "Growth behavior of superconducting $\mathrm{DyBa}_{2} \mathrm{Cu}_{3} \mathrm{O}_{7-x}$ thin films deposited by inclined substrate deposition for coated conductors", Acta Mater, vol. 60, 6592-6600 (2012).

[6] S. Fujita, M. Daibo, M. Igarashi, R. Kikutake, K. Kakimoto, Y. Iijima, M. Itoh and T. Saitoh. "In-field critical current property of IBAD/PLD coated conductors", J Phys Conf Ser, vol. 507 (2014) Art. ID. 022007.

[7] Hongbin Jian, Dingfu Shao, Zhaorong Yang, Xuebin Zhu and Yuping Sun. "J $J_{c}$ enhancement and flux pinning in $\mathrm{Y}_{1-x} \mathrm{Gd}_{x} \mathrm{BCO}$ and $(\mathrm{Gd}, \mathrm{Eu})$ codoped $\mathrm{Y}_{0.9-y} \mathrm{Eu}_{y} \mathrm{Gd}_{0.1} \mathrm{BCO}$ thin films by TFA-MOD”, Phys $C$, vol. 488, 39-45 (2013).

[8] T. J. Haugan, T. A. Campbell, N. A. Pierce, M. F. Locke, I. Maartense and P. N. Barnes. "Microstructural and superconducting properties of $\left(\mathrm{Y}_{1-x} \mathrm{Eu}_{x}\right) \mathrm{Ba}_{2} \mathrm{Cu}_{3} \mathrm{O}_{7-\delta}$ thin films: $\mathrm{x}=0-1 "$, Supercond Sci Technol, vol. 21 (2008) Art. ID. 025014.

[9] A. Radhika Devi, V. Seshu Bai, P. V. Patanjali, R. Pinto, N. Harish Kumar and S. K. Malik. "Enhanced critical current density due to flux pinning from lattice defects in pulsed laser ablated $\mathrm{Y}_{1-x} \mathrm{Dy}_{x} \mathrm{Ba}_{2} \mathrm{Cu}_{3} \mathrm{O}_{7-\delta}$ thin films", Supercond Sci Technol, vol. 13, 935939 (2000).

[10] Hongbin Jian, Zhenzhen Hui, Zhaorong Yang, Xuebin Zhu and Yuping Sun. "Enhanced $\mathrm{J}(\mathrm{c})$ in $\mathrm{YBa}_{2} \mathrm{Cu}_{3} \mathrm{O}_{7-d}$ Thin Films by Low-Level $\mathrm{Cr}$ Doping", IEEE Trans Appl Supercond, vol. 23, 5 (2013), Art. ID. 6568949.

[11] Hongbin Jian, Zhaorong Yang, Xuebin Zhu and Yuping Sun, "Effect of $\mathrm{Zr}$ addition on critical current density of $(\mathrm{Y}, \mathrm{Gd}) \mathrm{Ba}_{2} \mathrm{Cu}_{3} \mathrm{O}_{y}$ and (Y,Eu,Gd) $\mathrm{Ba}_{2} \mathrm{Cu}_{3} \mathrm{O}_{y}$ thin films depositedby TFA-MOD process", Phys Stat Solidi A, vol. 210, 8, 16471651 (2013).

[12] S.M. Choi, G. M. Shin and S. I. Yoo. "Flux pinning characteristics of Sn-doped YBCO film by the MOD process", Phys C, vol. 485, 154-159 (2013).

[13] Masashi Miura, Takeharu Kato, Masateru Yoshizumi, Yutaka Yamada, Teruo Izumi, Tsukasa Hirayama and Yuh Shiohara. "Rare Earth Substitution Effects and Magnetic Field Dependence of Critical Current in $\mathrm{Y}_{1-x} \mathrm{RE}_{x} \mathrm{Ba}_{2} \mathrm{Cu}_{3} \mathrm{O}_{y}$ Coated Conductors with Nanoparticles ( $\mathrm{RE}=\mathrm{Sm}$, Gd)", Appl Phys Express, vol. 2 (2009) Art. ID. 023002.

[14] J. L. MacManus-Driscoll, S. R. Foltyn, B. Maiorov et al. "Rare earth ion size effects and enhanced critical current densities in $\mathrm{Y}_{2 / 3} \mathrm{Sm}_{1 / 3} \mathrm{Ba}_{2} \mathrm{Cu}_{3} \mathrm{O}_{7-x}$ coated conductors", Appl Phys Lett, vol. 86, 3, 032505 (2005).

[15] H. Wang, J. L. Macmanus-Driscoll, S. R. Foltyn et al. "Materials science challenges for high-temperature superconducting wire". Nat Mater, vol. 6, 9, 631-642 (2007).

[16] L. Molina-Luna, S. Kaskel, B. Holzapfel et al. "BaHfO3 artificial pinning centres in TFA-MOD-derived YBCO and GdBCO thin films", Supercond Sci Tech, vol. 28, 11, 114002 (2015).

[17] Z. Aabdin, M. Drrschnabel, M. Bauer, R. Semerad, V. Groe, W. Prusseit and O. Eibl. "Growth behavior of $\mathrm{DyBa}_{2} \mathrm{Cu}_{3} \mathrm{O}_{7-d}$ thin films deposited by inclined substrate deposition for coated conductors", Phys Proc, vol. 36, 1445-1449 (2012).

[18] M. Derrschnabel, Z. Aabdin, M. Bauer, R. Semerad, W. Prusseit, O. Eibl, O. " $\mathrm{DyBa}_{2} \mathrm{Cu}_{3} \mathrm{O}_{7-x}$ superconducting coated conductors with critical currents exceeding $1000 \mathrm{~A} \mathrm{~cm}^{-1}$ ", Supercond Sci Tech, vol. 25, 105007 (2012).

[19] E. S. Hellman and E. H. Hartford. "Synthesis of new oxide materials by molecular beam epitaxy: the Dy-Ba-Cu-O and Ba-K-Bi-O systems", Phys C 190, 31-34, (1991).

[20] R. C. Budhani, H. Wiesmann, M. W. Ruckman, and R. L. Sabatini, "Epitaxial growth of Dy-Ba-Cu-O superconductor on (100)SrTiO3 using reactive and activated reactive evaporation processes", AIP Conf Proc, 182, 155 (1989)

[21] Y. Zhao, W. Wu, X. Tang, N. H. Andersen, Z. Han and J. Grivel. "Epitaxial growth of $\mathrm{YBa}_{2} \mathrm{Cu}_{3} \mathrm{O}_{7-x}$ films on $\mathrm{Ce}_{0.9} \mathrm{La}_{0.1} \mathrm{O}_{2-y}$ buffered yttria-stabilized zirconia substrates by an all-chemical-solution route", Cryst Eng Comm, vol. 16, 4369-4372 (2014).

[22] M. H. Pu, Y. Feng, P.X. Zhang, L. Zhou, J.X. Wang. "Investigating the flux pinning in high temperature superconductors more accurately", Phys C, vol. 386, 47-51 (2003).
[23] J. B. Nelson and D. P. Riley. "An experimental investigation of extrapolation methods in the derivation of accurate unit-cell dimensions of crystals", Proc Phys Soc, vol. 57, 160-177 (1945).

[24] Yeon-Soo Kim, Hyeoung-Ho Park, Young-soon Kim and Hyung-Shik Shin. "Preparation of $\mathrm{Y}_{1-x} \mathrm{Yb}_{x} \mathrm{Ba}_{2} \mathrm{Cu}_{3} \mathrm{O}_{7-y}$ Superconducting Films by Chemical Vapor Deposition", Korean J Chem Eng, vol. 17, 4, 473$476(2000)$

[25] A. El Ali, K. A. Azez, I. A. Al-Omari, J. Shobaki, M. K. Hasan (Qaseer), B. A. Albiss, Kh. Khasawnieh, Kh.A. Ziq and A. F. Salem. "The paramagnetic contribution in the magnetization behavior of $\mathrm{Y}_{1-x} \mathrm{Gd}_{x} \mathrm{Ba}_{2} \mathrm{Cu}_{3} \mathrm{O}_{7}$ ", Phys B, vol. 321, 320-323 (2002).

[26] K. Miyachi, K. Sudoh, Y. Ichino, Y. Yoshida and Y. Takai. "The effect of the substitution of $\mathrm{Gd}$ for $\mathrm{Ba}$ site on $\mathrm{Gd}_{1+x} \mathrm{Ba}_{2-x} \mathrm{Cu}_{3} \mathrm{O}_{6+d}$ thin films", Phys C, vol. 392-396, 1261-1264 (2003).

[27] F. Wang, J. Lin, X. N. Xu, L. K. Xu, L. J. Shen, X. S. Wu, X. Jin, C. C. Lam and S. S. Jiang. "Spin Gap Characteristic of $\mathrm{Y}\left(\mathrm{Ba}_{1-x} \mathrm{Gd}_{x}\right)_{2} \mathrm{Cu}_{3} \mathrm{O}_{7-d}$ ", J Supercond Nov Magn, vol. 13, 393-400 (2000).

[28] K. Zhang, B. Dabrowski, C. U. Segre, D. G. Hinks, I. K. Schuller, J. D. Jorgensen and M. Slaski. "Solubility and superconductivity in $\mathrm{RE}\left(\mathrm{Ba}_{2-x} \mathrm{RE}_{x}\right) \mathrm{Cu}_{3} \mathrm{O}_{7+d}$ systems (RE=Nd, Sm, Eu, Gd, Dy)", J. Phys. C: Solid State Phys., vol. 20, 935-940 (1987).

[29] S. I. Yoo, N. Sakai, H. Takaichi, T. Higuchi and M. Murakami. "Melt processing for obtaining $\mathrm{NdBa} 2 \mathrm{Cu} 3 \mathrm{O}$ y superconductors with high $\mathrm{T}_{c}$ and large $\mathrm{J}_{c}$ ", Appl Phys Lett, vol. 65, 633-635 (1994).

[30] D. A. Cardwell, D. S. Ginley. Handbook of Superconducting Materials Volume 1: Superconductivity, Materials and Processes. IOP Plublishing Ltd 2003 (2002).

[31] R. Flkiger, C. Senatore, M. Cesaretti, F. Buta, D. Uglietti and B Seeber. "Optimization of $\mathrm{Nb}_{3} \mathrm{Sn}$ and $\mathrm{MgB}_{2}$ wires", Supercond Sci Technol, vol. 21, 5, (2008) Art, ID. 054015.

[32] A. Guarino, A. Leo, G. Grimaldi, N. Martucciello, C. Dean, M. N. Kunchur, S. Pace and A. Nigro. "Pinning mechanism in electron-doped HTS $\mathrm{Nd}_{1.85} \mathrm{Ce}_{0.15} \mathrm{CuO}_{4-\delta}$ epitaxial films", Supercond Sci Technol, vol. 27 (2014) Art. ID. 124011.

[33] D. Dew-Hughes. "Flux pinning mechanisms in type II superconductors", Phil Mag, vol. 30, 293-305 (1974).

[34] A. Crisan, V. S. Dang, G. Yearwood, P. Mikheenko, H. Huhtinen and P. Paturi. "Investigation of the bulk pinning force in YBCO superconducting films with nano-engineered pinning centres", Phys $C$, vol. 503, 89-93 (2014). 